\title{
Can Nepal achieve nutritional targets by 2030? A trend analysis of childhood undernutrition in Nepal from 2001 to 2016
}

\author{
Sasmita Poudel Adhikari ${ }^{1}$, Huan Zhou ${ }^{1, *}$, Ramesh Adhikari ${ }^{2}$, Ruixue Ye ${ }^{1}$, \\ Khaled al-Zangabila', Qingzhi Wang ${ }^{1}$ and Thankam S Sunil ${ }^{1,3}$ \\ 'Department of Health and Social Behavior Science, West China School of Public Health and West China Fourth \\ Hospital, Sichuan University, Chengdu 610041, People's Republic of China: ${ }^{2}$ Padma Kanya Multiple Campus, \\ Tribhuvan University, Kathmandu, Nepal: ${ }^{3}$ Department of Public Health, University of Tennessee, Knoxville, USA
}

Submitted 22 April 2020: Final revision received 8 January 2021: Accepted 18 January 2021: First published online 21 January 2021

\begin{abstract}
Objective: This study assesses the prevalence of childhood undernutrition from 2001 to 2016 and estimate projections of undernutrition for 2016-2030 in Nepal. Design: The study used data from four rounds of a cross-sectional survey of Nepal Demographic and Health Survey (NDHS) conducted in 2001, 2006, 2011 and 2016. Descriptive analyses were conducted to calculate prevalence, binary logistic regression was used to test the significance of trends over time and autoregressive integrated moving average model was used to forecast the prevalence of childhood undernutrition.

Settings: The children and household member datasets from four NDHS were merged to assess the trends of childhood undernutrition in Nepal.

Participants: A total of 16613 children (8399 male and 8214 female) under 5 years of age were selected for anthropometric measurements using a stratified cluster random sampling method.

Results: Overall results show a decline in prevalence of stunting from $57.2 \%$ to $35.8 \%(P<0.001)$, underweight from $42.7 \%$ to $27 \%(P<0.001)$ and wasting from $11.2 \%$ to $9.7 \%(P<0.05)$ from 2001 to 2016 . However, different population subgroups have a higher prevalence of undernutrition than national average. Further, the analyses show that the prevalence of stunting will decline to $14.3 \%$ and wasting to $8.4 \%$ by 2030 .

Conclusion: A remarkable decrease in the prevalence of stunting and underweight has been observed over the last 15 years. Nepal is likely to achieve the nutritional targets for stunting but not for wasting by 2030. Given large subpopulation variations, further improvement in undernutrition require more specific, targeted and localised programmes.
\end{abstract}

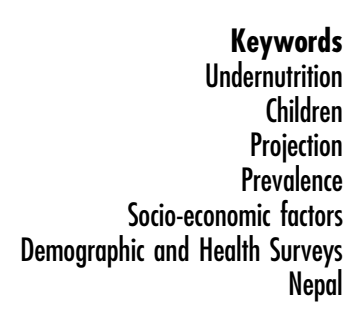

Childhood undernutrition is a major public health problem and accounts for an increased risk of morbidity, mortality and cognitive dysfunction among children under 5 years of age ${ }^{(1,2)}$. It remains an important public health issue globally, with $21.3 \%$ of the world's children experiencing stunting, $6.9 \%$ wasting and $5.6 \%$ overweight in $2019^{(3)}$. These global averages, however, can obscure different regional trends. As an example: from 2001 to 2019, global prevalence of stunting declined from $32.4 \%$ to $21.3 \%$; this substantial decline was certainly reflected in Asia (from $37.8 \%$ to $21 \cdot 8 \%)^{(3)}$. Previous studies ${ }^{(2,4-9)}$ have provided insights on global burden of undernutrition and helped raise awareness about the significance of early nutrition in the health of children with the evidence on the importance of enhancing nutrition-specific and nutrition-sensitive programmes for the prevention of undernutrition. Different nutritional promotion programmes, evidence-based interventions and policy commitments worldwide have contributed to a global reduction in undernutrition. However, undernutrition continues to be prevalent in low-and middle-income countries and large disparities persist between developed and developing countries ${ }^{(7)}$, affecting millions of children ${ }^{(1,2,10)}$. 
South Asia reported the highest prevalence of stunting (31.7\%) and wasting (14.3\%) and had 55.9 million children with stunting in $2019^{(3)}$.

Data on childhood undernutrition from Nepal show both the incredible progress this country has made and how much more work needs to be done to fully address childhood undernutrition. Nepal alone reduced stunting from $57 \cdot 2 \%$ to $35.8 \%$ during $2001-2016^{(11)}$, which is so far the fastest recorded reduction in stunting in the world over the past two decades ${ }^{(11,12)}$, in spite of the previous 10 years of civil war (1996-2006) and political instability until $2011^{(12,13)}$. Despite these remarkable improvements, undernutrition remains unacceptably high in Nepal, with a stunting prevalence reported at $36 \%$, wasting at $10 \%$ and underweight at $27 \%$ in $2016^{(11)}$. However, prevalences widely vary based on place of residence, development regions, ecological zones and socio-economic groups in Nepal. Relying only on overall national trends may mask widening socio-economic inequalities and alarmingly high prevalence of undernutrition ${ }^{(11,14,15)}$. While national statistics can be helpful, a stratified analysis is important in evaluating group variations within a country and is essential in informing policy designs for more focused programmes.

To improve the nutritional wellbeing of its population, the Government of Nepal (GoN) has initiated multiple national nutritional programmes under the Department of Health Services and has developed a coordinated approach with relevant sectors and stakeholders ${ }^{(16)}$. Since its membership to the Scaling Up Nutrition (SUN) movement in 2011, Nepal has adopted the Multi-Sector Nutrition Plan (MSNP) in 2012, which builds upon past efforts to specifically reduce maternal and child malnutrition $^{(16,17)}$. The GoN is devoted to achieving internationally agreed World Health Assembly's (WHA) global nutrition targets by 2025 and Goal 2 of Sustainable Development Goals (SDG) on zero hunger by $2030^{(16)}$. The global nutritional targets aim to reduce the number of stunted children under 5 years of age by $40 \%$ and childhood wasting to less than $5 \%$ by $2025^{(18)}$. Similarly, the target under SDG 2.2 includes ending all forms of malnutrition by 2030, including achieving, by 2025, the internationally agreed targets on stunting and wasting in children under 5 years of age, and addresses the nutritional needs of adolescent girls, pregnant and lactating women, and older persons ${ }^{(19)}$. In this context, GoN has set a target of lowering the prevalence of stunting to $24 \%$ by 2025 and to $15 \%$ by 2030 , and reducing wasting to less than $5 \%$ by 2025 and to $4 \%$ by $2030^{(16)}$. In addition, GoN has set a national target of reducing underweight to $15 \%$ by 2025 and to $10 \%$ by $2030^{(16)}$.

Monitoring the progress of nutritional status with projections in different socio-demographic and economic groups help policymakers understand the achievements and challenges faced in different population subgroups. This will be helpful in formulating programmes for the prevention of nutrition-related problems and designing strategies to meet
WHA nutritional targets by 2025 and SDG by 2030. Three types of undernutrition (stunting, wasting and underweight) are used holistically to assess childhood nutritional status reflecting different biological processes and are essential in tailoring different interventions ${ }^{(2,20,21)}$. Stunting, a sign of chronic undernutrition, is caused by long-term insufficient nutrient intake and repeated infections, whereas wasting is a measure of acute undernutrition as the result of acute food shortage or illness ${ }^{(2,21)}$. Underweight, on the other hand, occurs when children fail to reach an expected weight for their age, either due to acute undernutrition, chronic undernutrition or both ${ }^{(21)}$. A few published reports have considered all three types of undernutrition ${ }^{(12,22,23)}$; however, most of the scientific journal articles have analysed undernutrition trends focusing only on stunting ${ }^{(13-15,17)}$ and wasting ${ }^{(13)}$. Therefore, there is a strong need for empirical studies to use all three types of undernutrition (i.e. stunting, wasting and underweight) together to understand current undernutrition trends and make accurate projections of future trends. This is essential not only for designing future programmes but also in assessing if the GoN can meet its nutritional targets.

This study focuses on two main objectives: (1) analysis of the disaggregated trends of undernutrition among different socio-demographic and economic subgroups of children under 5 years of age and (2) forecast prevalence of stunting and wasting to inform progress towards achieving nutritional targets of WHA by 2025 and SDG by 2030 and national targets for underweight during the same time frame.

\section{Methods}

\section{Study design}

The present study is a secondary analysis of the data from four rounds of Nepal Demographic and Health Survey (NDHS) conducted in 2001, 2006, 2011 and 2016 to analyse trends in childhood undernutrition. NDHS is a nationally representative, cross-sectional survey on varieties of demographic, health and nutrition information conducted every 5 years since 1996 . The survey followed a two-stage and three-stage stratified cluster random sampling design. More details about the sampling method for all surveys, data collection, topics and procedures can be obtained from NDHS reports ${ }^{(11,22-24)}$.

\section{Description of datasets}

The children and household member datasets from four NDHS were merged and pooled together to track anthropometric measures and to evaluate undernutrition trends of children under 5 years. For the 2001 survey datasets, separate files of height-weight recode and wealth recode were merged with children and household member datasets before they were pooled together with other survey years. The study population included a total of 39175 households with a response rate of $99.6 \%$ (2001), 96.6\% 
Table 1 Information on four Nepal Demographic and Health Surveys included in data analysis

\begin{tabular}{|c|c|c|c|c|c|c|}
\hline \multirow[b]{2}{*}{$\begin{array}{l}\text { Survey } \\
\text { years }\end{array}$} & \multirow[b]{2}{*}{ Data collection date } & \multirow[b]{2}{*}{$\begin{array}{l}\text { Household } \\
\text { number }\end{array}$} & \multirow[b]{2}{*}{$\begin{array}{l}\text { Household } \\
\text { response rate (\%) }\end{array}$} & \multicolumn{3}{|c|}{ Children 0-59 months age } \\
\hline & & & & $\begin{array}{l}\text { Sample of anthropometric } \\
\text { measurements }(n)\end{array}$ & $\begin{array}{c}\text { Mean age } \\
\text { (months) }\end{array}$ & $\begin{array}{c}\% \\
\text { Male } \\
\end{array}$ \\
\hline NDHS 2001 & End January-End June 2001 & 8602 & $99 \cdot 6$ & 6442 & 30 & $49 \cdot 1$ \\
\hline NDHS 2006 & 5 February-18 August 2006 & 8707 & $99 \cdot 6$ & 5258 & 30 & $51 \cdot 4$ \\
\hline NDHS 2011 & 2 February-14 June 2011 & 10826 & $99 \cdot 4$ & 2485 & 30 & $51 \cdot 2$ \\
\hline NDHS 2016 & 19 June 2016-31 January 2017 & 11040 & $98 \cdot 5$ & 2428 & 30 & 52 \\
\hline Total & & 39175 & & 16613 & 16613 & 8400 \\
\hline
\end{tabular}

(2006), 99.4\% (2011) and 98.5\% (2016) $)^{(11,22-24)}$. This study included 16613 children under 5 years of age as a sample for the analysis (Table 1).

\section{Measurements and variables}

Child anthropometric measurements (i.e. weight and height) were obtained for those aged 6-59 months in all four surveys. Weight was measured while lightly dressed with lightweight seca infant scales with a digital display (seca model 878) with a precision of \pm 100 gram, designed and supplied by UNICEF. Similarly, height was measured with a measuring board (Shorr Boards) with precision to 1 millimetre. The recumbent length was measured for children younger than 24 months, and standing height was measured for older children above 24 months ${ }^{(11,22-24)}$.

Anthropometric measurements were used to generate information on prevalence of undernutrition (stunting, wasting and underweight). Stunting is defined as heightfor-age $z$ score that is 2 SD or less, underweight is defined as weight-for-age $z$ score under $2 \mathrm{SD}$ or less, and wasting is defined as weight-for-height $z$ score under 2 SD or less ${ }^{(25)}$. The $z$ scores (height-for-age $z$ score, weight-for-age $z$ score and weight-for-height $z$ score) are calculated using software based on the WHO Anthro program version 3.2.2 (WHO, 2011) and the macros for statistical packages. The WHO 2006 flags were used for cleaning and excluding cases with $z$ scores beyond specified lower or upper cutoffs for each type of undernutrition ${ }^{(26)}$.

An ecological framework ${ }^{(27)}$ with two levels including individual- and community-level characteristics was used to explore nutritional status. The explanatory variables representing individual-level analyses were child age, sex of children, mother's education (no education, primary, secondary and higher) and wealth index. The wealth index has five categories (poorest, poorer, medium, richer and richest) and was developed using a principal component analysis to combine information on the household's ownership of different assets or access to substantial goods. Explanatory variables representing community-level analyses include place of residence (rural/urban), ecological zones (Mountain, Hill and Terai) and development regions (eastern, central, western, mid-western and far-western). Development regions in Nepal are regional administrative units divided for balanced and proportionate development.
All categories within each explanatory variable were used as categorised in $\mathrm{NDHS}^{(11,22-24)}$.

\section{Statistical analysis}

Descriptive, logistic regressions and forecast analyses were performed. Prevalence and CI were calculated through the descriptive analyses. A binary logistic regression was used to test the significance of trends (Wald Chi-Squared test) over time. An autoregressive integrated moving average model was used to forecast the prevalence of undernutrition until 2030 based on the past prevalence in 2001, 2006, 2011 and 2016 .

The assumptions used in the autoregressive integrated moving average model for forecasting are that it uses past data to estimate future events assuming that the time series follows linear and normal distribution, and the data remain stable stationary. A model that shows stationary is the one that shows constancy to the data over time ${ }^{(28,29)}$. The model is written in the form of autoregressive integrated moving average ( $\mathrm{p}, \mathrm{d}$ and $\mathrm{q}$ ) where $\mathrm{p}$ is the order of the autoregressive process, $d$ is the order of the data stationary and $q$ is the order of the moving average process. The model with $\mathrm{p}, \mathrm{d}$, $q(0,0,0)$ was used as the best-fit model in our study for forecasting. Further, three indicators were used to access the model fit including root mean square error, mean absolute percentage error and mean absolute error. The findings in this study showed that the selected autoregressive integrated moving average model captured the dynamics in the series and produced forecasted values that had minimal forecast errors when compared with the actual undernutrition status in the validation period.

Data analyses were performed in Statistical Package for Social Sciences (SPSS) version 23 (IBM Corp). All analyses were stratified by sex. The present analysis considers $P \leq 0.05$ as statistically significant. The DHS sampling design includes both under- and oversampling; therefore, to adjust the survey design effect, all analyses were performed by applying sample weights provided by $\mathrm{DHS}^{(26)}$.

\section{Results}

After excluding 822 children with missing values for anthropometric measurements, the number of children 


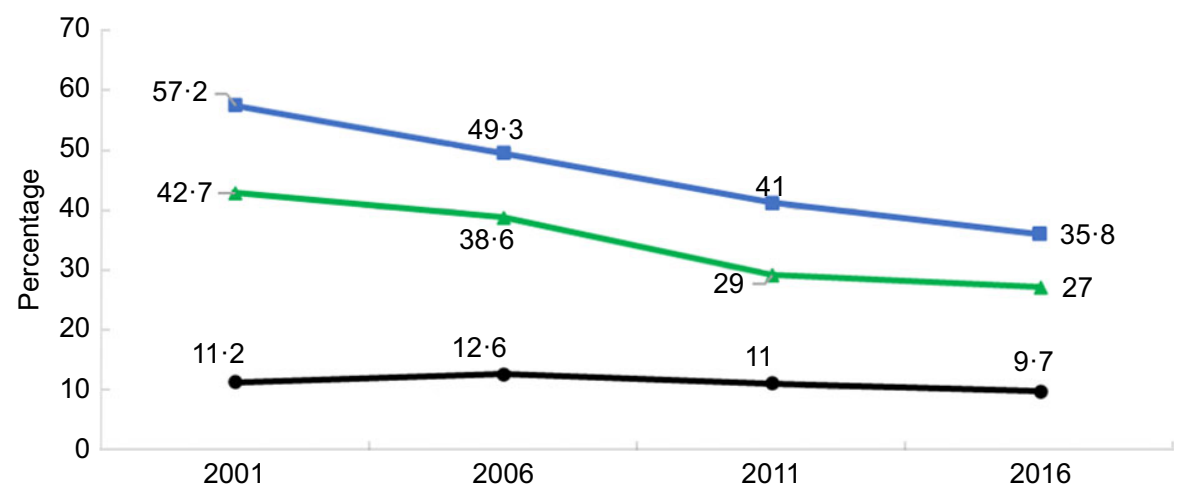

Fig. 1 (colour online) Trends in undernutrition at the national level, 2001-2016. $\rightarrow-$ Stunting; $\rightarrow$-Wasting; $\_-$Underweight

included in the analysis for the study from 2001 to 2016 is 16606 for stunting, 16602 for wasting and 16613 for underweight. Children mean age in all NDHS surveys was 30 months (1.6 SD). On average, sampled children were 102 males per every 100 females (Table 1).

\section{National nutritional trends in children}

Nationally, all three undernutrition indicators improved during the study period. The prevalence of stunting decreased from $57.2 \%$ to $35.8 \%(P<0.001)$, underweight from $42.7 \%$ to $27 \%(P<0.001)$ and wasting from $11.2 \%$ to $9.7 \%(P<0.05)$ among children $0-59$ months of age (Fig. 1$)$. Both males and females at the national level experienced decline in the prevalence of stunting and underweight $(P<0.001)$. However, the declining trend for wasting was statistically significant only for males $(P=0.022)$ (see online supplementary material, Supplemental Tables 1-3).

\section{Detailed trends in stunting (beight-for-age)}

Sex-stratified analysis showed a decline in the stunting trend for all age groups $(P<0.05)$ except in $0-5$-monthold male children $(P=0 \cdot 133)$. The largest decrease (30 percentage points) was in the 36-47-month age group in both males and females throughout the 15-year period. The lowest decline of the prevalence of stunting in female children ( 7.4 percentage points) and the highest decline in male children ( 19.3 percentage points) were observed within the same group whose mothers received higher levels of education during the 15-year period. Similarly, the prevalence of stunting in 2016 was the highest in the poorest quintile (49.2\%). Stunting prevalence in rural females was reduced by almost double (18.3 percentage points) compared to urban females ( 8.6 percentage points) during the study period.

When separated by ecological zones, stunting prevalence decreased in all zones and for both sexes $(P \leq 0.001)$. Stunting prevalence in females in Hill decreased by 29.4 percentage points from 2001 to 2016. The prevalence of stunting in 2016 was the highest $(46.9 \%)$ in male children living in Mountain.
Furthermore, the highest improvement was found in the far-western region with a reduction of 25.7 percentage points among males during the study period (see online supplementary material, Supplemental Table 1).

\section{Detailed trends in wasting (weight-for-beight)}

A declining trend $(P<0.001)$ for wasting was found only for males aged 12-23 months. The highest reduction in wasting prevalence $(3.8$ percentage points) during the study period was found among females aged 1223 months. Sex-stratified wasting trends by mother's education were not statistically significant for any groups. The highest decrease in wasting prevalence was in male children whose mothers had primary education, which had decreased by $3 \cdot 2$ percentage points from 2001 to 2016. The highest decrease in wasting prevalence was observed in males in the middle quintile (decrease by 5.4 percentage points), while it increased by $2 \cdot 8$ percentage points among female children in the same wealth quintile from 2001 to 2016.

Rural areas showed no significant trend in decline in wasting from 2001 to $2016(P=0.494)$. The overall prevalence of wasting among urban males and females is almost similar in 2001 and 2016, with fluctuating trends in different survey years. When analysing wasting trends by ecological zone, declining trends in wasting prevalence were only found in those living in Terai $(P \leq 0.05)$. However, the prevalence of wasting in females living in Terai $(12.7 \%)$ was more than double compared to females living in Mountain (5.9\%) and Hill (6.3\%) in 2016. The highest decline in wasting was among females living in the central region (6.3 percentage points) from 2001 to 2016 (see online supplementary material, Supplemental Table 2).

\section{Detailed trends in underweight (weight-for-age)}

During the study period, maximum decline in underweight prevalence (23 percentage points) was observed among females aged 36-47 months. Trends in underweight vary based on maternal education, although generally, results suggest that underweight prevalence decreased as the 
mother's educational level increased. However, it is worth noting that the maximum decrease in underweight prevalence ( 12.7 percentage points) was experienced by female children whose mothers had no education during the study period.

Declining trends in underweight prevalence over 15 years were statistically significant $(P<0.001)$ in all wealth quintiles with the highest decrease observed in the poorest quintile from $51.8 \%$ to $32.9 \%$. Results show that both sexes experienced a decline in underweight prevalence $(P<0.05)$ in all ecological zones. From 2001 to 2016, the prevalence of underweight among females was reduced by 22.9 percentage points in Hill and by 14.2 percentage points in Mountain. The highest decrease in underweight prevalence was among female children in the central region (20.6 percentage points) in the same period (see online supplementary material, Supplemental Table 3).

\section{Forecast of prevalence for child undernutrition}

Figure 2 shows that the national prevalence of all three metrics will decline by 2030. Stunting prevalence will decline nationally to $21.6 \%$ in 2025 and to $14.3 \%$ in 2030. Similarly, underweight prevalence will decline to $15.5 \%$ in 2025 and to $9.8 \%$ in 2030, and wasting prevalence will decline to $9 \%$ in 2025 and to $8.4 \%$ in 2030 .

Stratifying the analysis by region showed that the prevalence of stunting in the mid-western region will be $30.7 \%$ in 2025 and $24 \%$ in 2030, while in the far-western region stunting is expected to be $23 \%$ in 2025 and $16 \%$ in 2030. Unfortunately, the trends for wasting prevalence in all development regions are expected to be higher than nutrition targets in 2025 and 2030. The underweight prevalence will remain high for the eastern region (18.1\% and $14.4 \%)$ and the mid-western region (20.3\% and $14.7 \%)$ both in 2025 and 2030 (Fig. 3).

When sorting by ecological zones, forecast results show that the prevalence of stunting will reach target levels in the Hill, where stunting is expected to be $16.2 \%$ in 2025 and $7 \cdot 1 \%$ in 2030 . The Terai is likely to achieve the stunting target for 2025 with a prevalence of $23.8 \%$. Similarly, targets for underweight will only be reached in the Hill, where underweight prevalence is expected to be $6.4 \%$ in 2025 and no underweight cases in 2030. However, the targets for wasting will not be achieved in any of the ecological zones (Fig. 4).

\section{Discussion}

The undernutrition trend analysis stratified by sociodemographic, economic and child characteristics from 2001 to 2016 showed that Nepal has made remarkable progress in reducing undernutrition, especially in regard to stunting and underweight. Nepal's progress in fighting undernutrition over this period can largely be attributed to increased access to health care, increased maternal education, improved sanitation and increased household wealth ${ }^{(12,13,30)}$. However, our trend analysis also showed that there is still considerable room for improvement and a need for more effective programmes and inter-sectoral coordination ${ }^{(12)}$ to achieve nutritional targets of WHA 2025 and SDG 2030.

At the national level, childhood undernutrition, as measured by stunting and underweight, decreased significantly. From 2001 to 2016, stunting prevalence decreased by 21.4 percentage points and underweight prevalence decreased by 15.7 percentage points. Projections based on these results suggest that stunting prevalence will be $21.6 \%$ in 2025 and $14.3 \%$ in 2030. Similarly, wasting prevalence will be $9 \%$ in 2025 and $8.4 \%$ in 2030. Based on the above findings, Nepal appears on track to achieve the WHA's nutrition targets for stunting but unlikely to achieve the targets for wasting (Fig. 2).

Although much progress has been made at reducing the prevalence of undernutrition at the national level, analysis showed that national average masks disparities across socio-economic groups, developmental regions, ecological zones and places of residence. The results suggest that rural areas have experienced remarkable reductions in undernutrition prevalence compared to urban areas. Nevertheless, undernutrition prevalence in rural areas remains

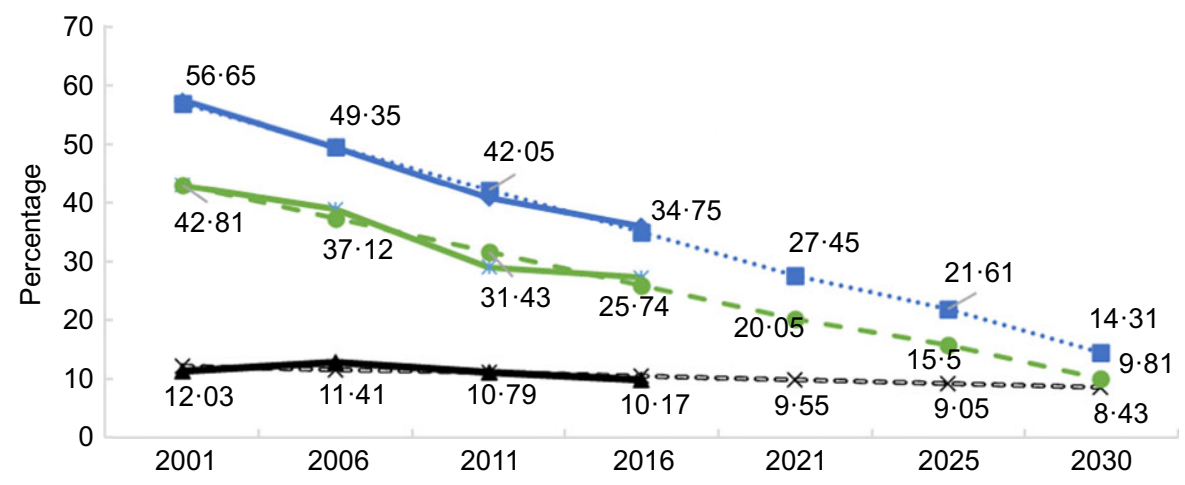

Fig. 2 (colour online) Forecast of prevalence for child undernutrition. $\rightarrow$ Actual stunting; $\cdots$ - predicted stunting; $\rightarrow$ actual wasting; $\times$ predicted wasting; $-*$ actual underweight; -- predicted underweight 


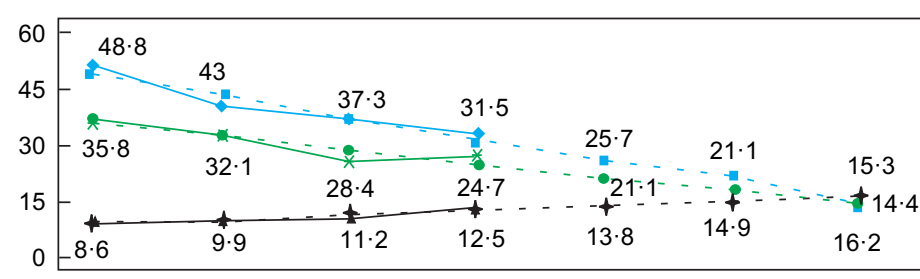

Eastern

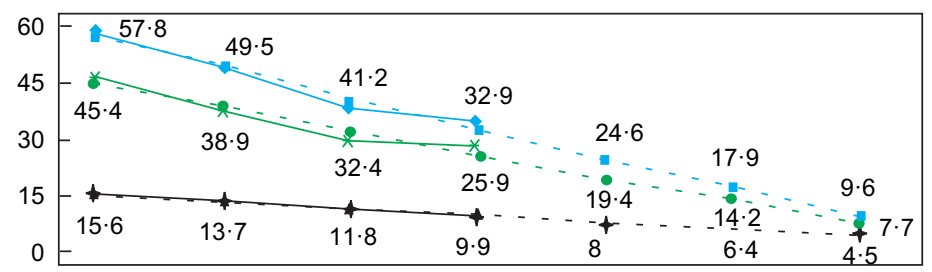

Central
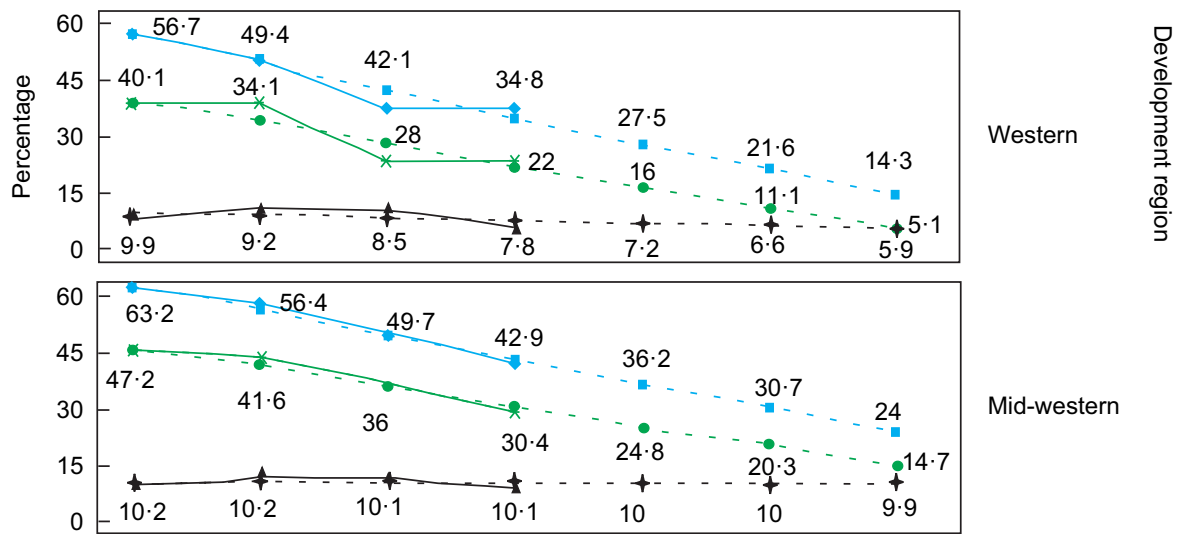

Mid-western

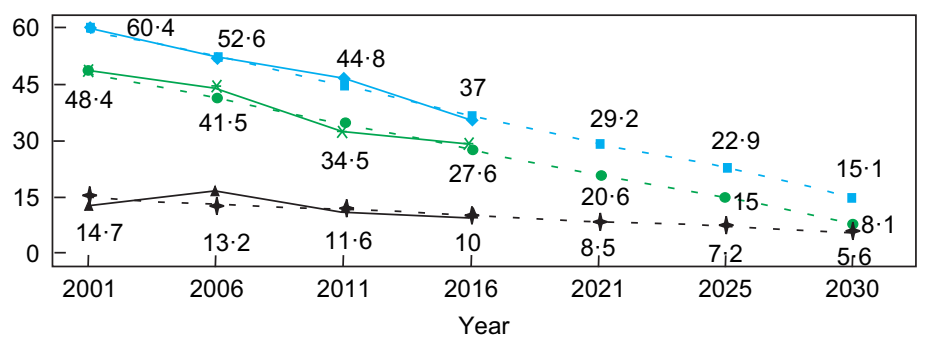

Far-western

Fig. 3 (colour online) Forecast of undernutrition by development region. $-\leftarrow$ Stunting actual; $--\bullet-$ underweight actual; $\rightarrow-$ wasting actual; --- stunting predicted; --*- underweight predicted; ----- wasting predicted

higher than national averages. Stunting in rural areas was 4.4 percentage points higher than the national average and $10 \cdot 2$ percentage points higher than urban areas in 2016 (see online supplementary material, Supplemental Table 1). Similarly, the underweight prevalence in rural areas is 7.7 percentage points higher than in urban areas and 4.1 percentage points higher than the national average (see online supplementary material, Supplemental Table 3). Wasting in children has seen less improvement and more fluctuating trends in both urban and rural areas among both sexes (see online supplementary material, Supplemental Table 2). These findings contrast with trend studies in Peru, where improvements in stunting, wasting and underweight were found to be higher in urban areas ${ }^{(31,32)}$. The huge urban-rural disparities in Peru despite different national-level social programmes and policy enhancement in the reduction of malnutrition is due to the challenges faced in implementing these programmes in rural areas until the mid-2000s due to internal conflict ${ }^{(31)}$. A similar study conducted in Ghana ${ }^{(33)}$ reported statistically significant declining underweight trends for both males and females, and declining stunting and wasting trends only among males. However, our results showed statistically significant declining trends for stunting and underweight in both males and females. The difference in findings might be related to variation in culture, socio-economic status and care practices of children in both countries ${ }^{(34,35)}$.

The undernutrition prevalence varied depending on the ecological zone. Stunting in Mountain was higher than the national average by almost 11 percentage points in 2016, while wasting and underweight were high among children in Terai (Figs. 1 and 4). Stunting was reduced by 19.5 percentage points in Mountain and by 27.5 percentage points in Hill from 2001 to 2016, but the prevalence of stunting was $46.8 \%$ in Mountain in 2016, which remains unacceptably high compared to national and global estimates ${ }^{(7)}$. 


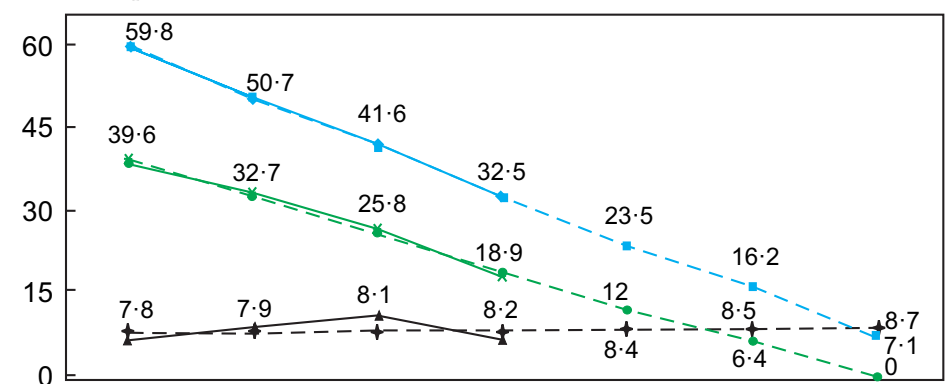

Hill

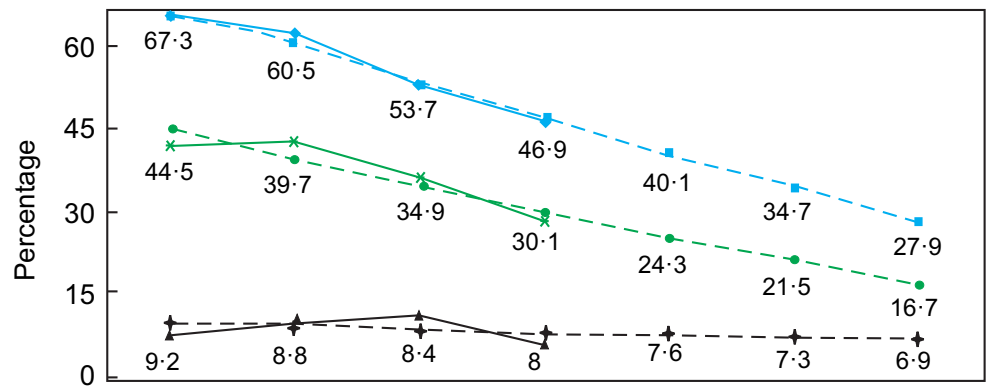

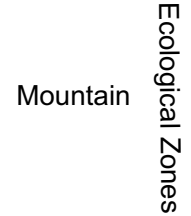

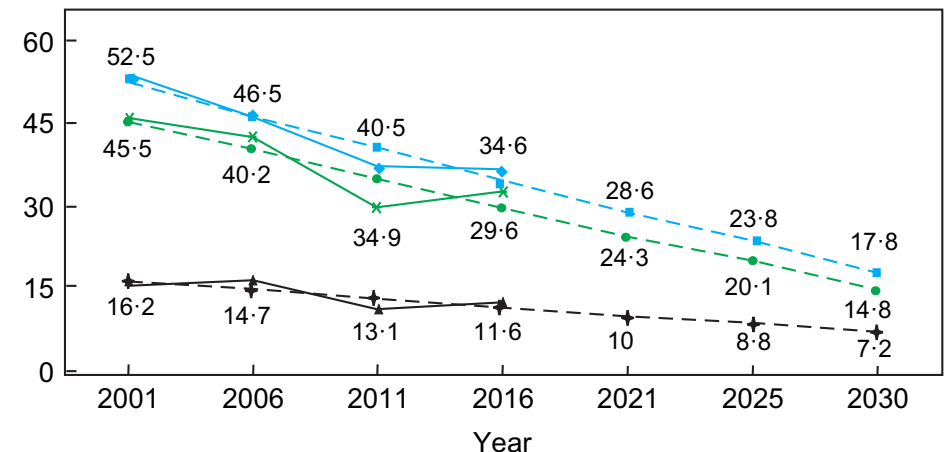

Terai

Fig. 4 (colour online) Forecast of undernutrition by ecological zones. $-\bullet$ Stunting actual; - -*- underweight actual; $\rightarrow-$ wasting actual; ---- stunting predicted; -.--- underweight predicted; -.--- wasting predicted

Another recent study examining ecological variations of stunting in Nepal found similar results of the highest prevalence of stunting in Mountain across all four survey years ${ }^{(15)}$. The wasting prevalence in female children living in Terai was 3 percentage points higher than national averages and was more than double the prevalence found in female children living in Hill and Mountain in 2016. The underweight prevalence in Hill was below the national average. Hill is likely to achieve WHA's and national targets for stunting by 2025 and 2030, but Mountain is unlikely to achieve either stunting or wasting targets, and Terai is unlikely to meet proposed targets for wasting (Fig, 4). In fact, Terai would need to reduce the current wasting prevalence by half in order to reach WHA 2025 and national targets.

While comparing the prevalence of undernutrition among different development regions, the central and far-western regions achieved the highest and similar declining trends in undernutrition compared to other three regions. The reduced prevalence in Nepal's central region is likely because the region has better access to basic resources such as health facilities and schools, especially compared to the far-western region ${ }^{(16,36)}$. However, reduced undernutrition prevalence in the far-western region can likely be attributed to active poverty alleviation government programmes, including Poverty Alleviation Fund, geographically targeted health and employment programmes, and targeted programmes for poorer and marginalised sections of the population ${ }^{(37)}$. The mid-western region has the highest levels of poverty and was highly affected during 1996-2006 by Maoist insurgency ${ }^{(38)}$. This region has the highest prevalence of stunting ( $42 \%)$ and underweight (29.1\%) which was 6 percentage points and 2 percentage points above the national average in 2016. The wasting prevalence was highest in the eastern region at $13.1 \%$, which was 3.4 percentage points above the national average. The projection suggests that the mid-western region will not be able to achieve WHA 2025 and SDG 2030 nutritional targets on stunting and wasting. Therefore, in order to meet the global and national nutritional targets, the GoN must provide additional resources to target-focused programmes in the mid-western region along with Mountain and Terai. In particular, programmes targeting wasting in all ecological zones and regions need to be prioritised by GoN, otherwise, these areas are unlikely to meet 
national targets. Our findings on regionally based inequalities in child undernutrition are consistent with other studies $^{(15,33,39)}$.

Our analysis showed that undernutrition prevalence decreased with improved levels of mothers' education (see online supplementary material, Supplemental Tables 1-3). Previous studies ${ }^{(5,12,15,32,40,41)}$ have also reported a similar finding between mother's education and undernutrition. The improvement in literacy rate among women from $28 \%$ in $2001^{(22)}$ to $66.7 \%$ in $2016^{(11)}$ might have contributed to lowering undernutrition among the children. The findings of our study also showed that the decrease in the prevalence of undernutrition was correlated with improved levels of wealth quintile. The stunting prevalence in the poorest quintile was high by 13.4 percentage points compared to the national prevalence of stunting in 2016. Moreover, the stunting gap between the poorest and the richest households seemed to have increased over time: in 2001, the stunting prevalence among the poorest quintile was only 1.5 times as high as the richest quintile, while in 2016, this gap increased to 3 times. Similarly, the wealth gap in the underweight prevalence between the poorest and richest quintiles increased from two times in 2001 to three times in 2016. However, during the period of 15 years, the poorest quintile also experienced a large decline in all three types of undernutrition. These results are consistent with other studies ${ }^{(14,39,40)}$. The decline in the stunting and underweight prevalence among the poorest and poorer quintiles may be related to the economic growth of the country since $1995 / 96$, in which poverty declined from $42 \%$ in 1995/96 to $25 \%$ in 2010 , food inadequacy reduced from $31 \%$ in $1999 /$ 2001 to $19 \%$ in $2011 / 13$, and education improved for those in the poorest quintile ${ }^{(36,42)}$.

Stunting and underweight were more prevalent among older children (aged 24-35 months). However, the prevalence of wasting was high in children aged 6-11 months compared to other age groups. Previous studies ${ }^{(41,43,44)}$ have reported an increased risk of undernutrition with an increase in the age of the child. The reason could be attributed to late introduction of low nutritional quality supplementary food to the child, unfulfilment of optimal food requirements of the child, and illnesses such as diarrhoea, acute respiratory infections and intestinal parasites to name a few ${ }^{(40,44-47)}$.

Nepal's improvements in childhood undernutrition might be influenced by a wide range of policies, programmes and projects dedicated to improve the health and nutritional status of mothers and young children conducted by the government with the support of various donor organisations, and other non-governmental organisations at the national and local levels ${ }^{(16,48,49)}$. The National Nutrition Policy guides nutrition strategic and programmatic direction within the health sector and MSNP focus on nutrition-specific and nutrition-sensitive programmes. Relevant programmes focused on children's growth, promotion of breast-feeding and improving complementary feeding practices. Similarly, capacity enhancement of community and health workers for screening and management of acute malnutrition along with supportive supervision, regular monitoring and behaviour change communication initiatives in nutrition are noteworthy interventions ${ }^{(16,48,49)}$. These interventions may have contributed to the improvement of nutrition behaviours, feeding practices, decrease in micronutrient deficiencies and reduction in undernutrition among the children under 5 years of age in $\mathrm{Nepal}^{(16,48)}$. Moreover, increased economic growth, standards of living, accessibility to development and communication infrastructures, and decreased poverty contributed to the reduction of undernutrition rates ${ }^{(37,42)}$. This economic growth is attributed to different programmes such as the Agriculture Support Programme, creation of Poverty Alleviation Fund, and integrated rural development programme ${ }^{(37)}$.

The sheer number of specific sectors and organisations that are working to reduce undernutrition highlights the importance of effective multi-sectoral nutritional sensitive strategies together with nutrition-specific interventions ${ }^{(9)}$. In addition, to achieve global nutrition targets, the GoN should strengthen and scale up nationwide nutrition programmes such as Maternal, Infant and Young Children Nutrition programme, micronutrient powder distribution linked with Infant and Young Child Feeding (IYCF), and MSNP-II Phase (2018-2022) ${ }^{(16)}$.

The study has some limitations. It is based on the crosssectional nature; hence, the results only suggest associations rather than causal inference. Moreover, the sample in subgroups analysis may not be representative due to a decrease in the power of statistical testing for trends as the sampling frame in this study was done on children 6-59 months old. Despite these limitations, the strength of this study is that it is based on a nationally representative survey collected over four rounds (2001-2016) with a large sample size and an average response rate of $98 \%$. NDHS used the same standardised data collection tools, and surveys were conducted by the same organisation for all four rounds, which helps keep the data consistent and accurate.

\section{Conclusion}

The study showed a notable decline in undernutrition, especially on stunting and underweight over the last 15 years in Nepal. However, substantial inequalities exist across socio-economic groups, development regions, ecological zones and places of residence. Moreover, Nepal is likely to achieve the global and national nutritional targets for stunting but unlikely to reach both targets related to wasting. The study provides scientific evidence useful for policymakers, planners and practitioners to understand the achievements and challenges faced by different subgroups. The need of multi-sectoral efforts, high political commitment and additional resources with targeted and 
focused programmes for different subgroups to meet the global and national nutritional targets is recommended.

\section{Acknowledgements}

Acknowledgements: The researchers would like to thank the DHS Program for providing access to the data for this study. The authors would like to thank all involved in the data collection and all the participant mothers and children of NDHS. We are also grateful to Jan Reinhardt, Basanta Raj Adhikari and Joseph Balikuddembe for insights to this manuscript. Financial support: None. Conflict of interest: None. Authorship: SPA designed the study, conducted statistical analysis, interpreted findings and discussion and wrote the first draft of the manuscript. HZ, RPA and SST supported in designing the study and result interpretation. RY, KZ and QW helped discuss the results. All the authors contributed to revision and approval of the final version of the manuscript. Ethics of human subject participation: This study analysis was based on secondary data and original research did not violate any ethics procedure; hence, it was exempted from the ethical approval process for further analysis and publication. Datasets were accessed through DHS programme upon written request with a clear explanation of the purpose of data use.

\section{Supplementary material}

For supplementary material accompanying this paper visit https://doi.org/10.1017/S1368980021000240

\section{References}

1. Bhutta ZA, Berkley JA, Bandsma RH et al. (2017) Severe childhood malnutrition. Nat Rev Dis Primers 3, 17067.

2. Black R, Allen LH, Bhutta ZA et al. (2008) Maternal and child undernutrition: global and regional exposures and health consequences. Lancet 371, 243-260.

3. United Nations Children's Fund (UNICEF), World Health Organization \& International Bank for Reconstruction and Development/The World Bank (2020) Levels and Trends in Child Malnutrition: Key Findings of the 2020 Edition of the Joint Child Malnutrition Estimates. Geneva: World Health Organization.

4. Bhutta ZA, Ahmed T, Black RE et al. (2008) What works? Interventions for maternal and child undernutrition and survival. Lancet 371, 417-440.

5. Bhutta ZA, Das JK, Rizvi A et al. (2013) Evidence-based interventions for improvement of maternal, child nutrition: what can be done, at what cost? Lancet 382, 452-477.

6. Gillespie S, Haddad L, Mannar V et al. (2013) The politics of reducing malnutrition: building commitment and accelerating progress. Lancet 382, 552-569.

7. Development Initiatives (2018) 2018 Global Nutrition Report: Shining a Light to Spur Action on Nutrition. Bristol: Development Initiatives.

8. Morris SS, Cogill B, Uauy R et al. (2008) Effective international action against undernutrition: why has it proven so difficult and what can be done to accelerate progress? Lancet 371, 608-621.

9. Ruel MT, Alderman H \& Maternal and Child Nutrition Study Group (2013) Nutrition-sensitive interventions and programmes: how can they help to accelerate progress in improving maternal and child nutrition? Lancet 382, 536-551.

10. Black RE, Victora CG, Walker SP et al. (2013) Maternal and child undernutrition and overweight in low-income and middle-income countries. Lancet 382, 427-451.

11. Ministry of Health, New Era \& ICF International (2017) Nepal Demographic and Health Survey 2016. Kathmandu: Ministry of Health, Government of Nepal.

12. Headey DD \& Hoddinott $J$ (2015) Understanding the rapid reduction of undernutrition in Nepal, 2001-2011. PLoS One 10, e 0145738

13. Cunningham K, Headey D, Singh A et al. (2017) Maternal and Child Nutrition in Nepal: examining drivers of progress from the mid-1990s to 2010s. Glob Food Secur 13, 30-37.

14. Angdembe MR, Dulal BP, Bhattarai K et al. (2019) Trends and predictors of inequality in childhood stunting in Nepal from 1996 to 2016. Int J Equity Health 18, 42.

15. Nepali S, Simkhada P \& Davies I (2019) Trends and inequalities in stunting in Nepal: a secondary data analysis of four Nepal demographic health surveys from 2001 to 2016. BMC Nutr 5, 19.

16. Department of Health Services (2018) Annual Report. Kathmandu: Ministry of Health and Population, Government of Nepal.

17. Devkota MD, Adhikari RK \& Upreti SR (2016) Stunting in Nepal: looking back, looking ahead. Matern Child Nutr 12, 257.

18. World Health Organization (2014) Global Nutrition Targets 2025: Policy Brief Series (WHO/NMH/NHD/14.2). Geneva: World Health Organization.

19. United Nations (2015) Sustainable Development Goals, Goal 2: end hunger, achieve food security and improved nutrition and promote sustainable agriculture. https://sdgs.un.org/ goals/goal2 (accessed September 2020).

20. Akhade KS (2018) Measuring malnutrition: needs a comprehensive indicator. Int J Community Med Public Health 5, 258-261.

21. World Health Organization (2010) Nutrition Landscape Information System Country Profile Indicators: Interpretation Guide. Geneva: World Health Organization.

22. Ministry of Health and Population, New Era \& ORC Macro (2002) Nepal Demographic and Health Survey 2001. Kathmandu: Ministry of Health, Government of Nepal.

23. Ministry of Health, New Era \& Macro International (2006) Nepal Demographic and Health Survey 2006. Kathmandu: Ministry of Health, Government of Nepal.

24. Ministry of Health, New Era \& ICF International (2011) Nepal Demographic and Health Survey 2011. Kathmandu: Ministry of Health, Government of Nepal.

25. World Health Organization (2006) WHO Child Growth Standards: Length/Height-for-Age, Weight-for-Age, Weightfor-Length, Weight-for-Height and Body Mass Index-forAge: Methods and Development. Geneva: World Health Organization.

26. Croft TN, Aileen M, Courtney K et al. (2018) Guide to DHS Statistics: DHS-7. Maryland: ICF.

27. Gregson J, Foerster SB, Orr R et al. (2001) System, environmental, and policy changes: using the social-ecological model as a framework for evaluating nutrition education and social marketing programs with low-income audiences. J Nutr Educ 33, S4-S15.

28. Brockwell PJ \& Davis RA (2002) Introduction to Time Series and Forecasting. New York: Springer.

29. Ho SL \& Xie M (1998) The use of ARIMA models for reliability forecasting and analysis. Comput Ind Eng 35, 213-216. 
30. Headey D, Hoddinott J \& Park S (2016) Drivers of nutritional change in four South Asian countries: a dynamic observational analysis. Matern Child Nutr 12, 210-218.

31. Loret de Mola C, Quispe R, Valle GA et al. (2014) Nutritional transition in children under five years and women of reproductive age: a 15-years trend analysis in Peru. PLoS One 9, e92550.

32. Urke HB, Mittelmark MB \& Valdivia M (2014) Trends in stunting and overweight in Peruvian pre-schoolers from 1991 to 2011: findings from the Demographic and Health Surveys. Public Health Nutr 17, 2407-2418.

33. Amugsi DA, Mittelmark MB \& Lartey A (2013) An analysis of socio-demographic patterns in child malnutrition trends using Ghana demographic and health survey data in the period 1993-2008. BMC Public Health 13, 960.

34. Frempong RB \& Annim SK (2017) Dietary diversity and child malnutrition in Ghana. Heliyon 3, e00298.

35. Raj A, McDougal LP \& Silverman JG (2015) Gendered effects of siblings on child malnutrition in South Asia: cross-sectional analysis of Demographic and Health Surveys from Bangladesh, India, and Nepal. Matern Child Health J 19, 217-226.

36. Central Bureau of Statistics (2011) Nepal living standards survey 2010/11. Kathmandu: National Planning Commission, Government of Nepal.

37. National Planning Commission (2016) Nepal and The Millennium Development Goals Final Status Report 2000-2015. Kathmandu: National Planning Commission, Government of Nepal.

38. Devkota B \& Van Teijlingen ER (2010) Understanding effects of armed conflict on health outcomes: the case of Nepal. Confl Health 4, 20.

39. Bredenkamp C, Buisman LR \& Van de Poel E (2014) Persistent inequalities in child undernutrition: evidence from 80 countries, from 1990 to today. Int J Epidemiol 43, 1328-1335.

40. Meshram II, Arlappa N, Balakrishna N et al. (2012) Trends in the prevalence of undernutrition, nutrient \& food intake and predictors of undernutrition among under five-year tribal children in India. Asia Pac J Clin Nutr 21, 568-576.

41. Sahu SK, Kumar SG, Bhat BV et al. (2015) Malnutrition among under-five children in India and strategies for control. J Nat Sci Biol Med 6, 18.

42. Uematsu H, Shidiq AR \& Tiwari S (2016) Trends and Drivers of Poverty Reduction in Nepal: a Historical Perspective. USA: Washington DCThe World Bank Group.

43. Das S \& Gulshan J (2017) Different forms of malnutrition among under five children in Bangladesh: a cross sectional study on prevalence and determinants. BMC Nutr $\mathbf{3}, 1$.

44. Endris N, Asefa H \& Dube L (2017) Prevalence of malnutrition and associated factors among children in rural Ethiopia. BioMed Res Int. Published online: 17 May 2017. doi: 10.1155/2017/ 6587853.

45. Saeed A, Abd H \& Sandstrom G (2015) Microbial aetiology of acute diarrhoea in children under five years of age in Khartoum, Sudan. J Med Microbiol 64, 432-437.

46. Seddon JA, Hesseling AC, Godfrey-Faussett P et al. (2013) Risk factors for infection and disease in child contacts of multidrug-resistant tuberculosis: a cross-sectional study. $B M C$ Infect Dis 13, 392.

47. LaBeaud AD, Singer MN, McKibben M et al. (2015) Parasitism in children aged three years and under: relationship between infection and growth in rural coastal Kenya. PLoS NeglTrop Dis 9, e0003721.

48. United Nations Children's Fund (2018) Water, Sanitation and Hygiene (WASH) and Nutrition in Nepal, with a Focus on Children under Five: Nepal Multiple Indicator Cluster Survey (MICS) 2014 Further Analysis Report. UNICEF Nepal Working Paper Series WP/2018/004. Kathmandu: United Nations Children's Fund.

49. United States Agency for International Development (2018) Nepal Nutrition profile. Kathmandu: United States Agency for International Development. 